\title{
Non-Darcy flow in oil accumulation (oil displacing water) and relative permeability and oil saturation characteristics of low-permeability sandstones
}

\author{
Zeng Jianhui ${ }^{1,2 *}$, Cheng Shiwei ${ }^{1,2}$, Kong Xu${ }^{1,3}$, Guo Kai ${ }^{1,2}$ \\ and Wang Hongyu ${ }^{1,2}$ \\ ${ }^{1}$ State Key Laboratory of Petroleum Resources and Prospecting, China University of Petroleum, Beijing 102249, China \\ ${ }^{2}$ School of Natural Resources and Information Technology, China University of Petroleum, Beijing 102249, China \\ ${ }^{3}$ CNPC Greatwall Drilling Company, Beijing 100101, China
}

(C) China University of Petroleum (Beijing) and Springer-Verlag Berlin Heidelberg 2010

\begin{abstract}
Hydrocarbon resources in low-permeability sandstones are very abundant and are extensively distributed. Low-permeability reservoirs show several unique characteristics, including lack of a definite trap boundary or caprock, limited buoyancy effect, complex oil-gas-water distribution, without obvious oil-gas-water interfaces, and relatively low oil (gas) saturation. Based on the simulation experiments of oil accumulation in low-permeability sandstone (oil displacing water), we study the migration and accumulation characteristics of non-Darcy oil flow, and discuss the values and influencing factors of relative permeability which is a key parameter characterizing oil migration and accumulation in low-permeability sandstone. The results indicate that: 1) Oil migration (oil displacing water) in lowpermeability sandstone shows non-Darcy percolation characteristics, and there is a threshold pressure gradient during oil migration and accumulation, which has a good negative correlation with permeability and apparent fluidity; 2) With decrease of permeability and apparent fluidity and increase of fluid viscosity, the percolation curve is closer to the pressure gradient axis and the threshold pressure gradient increases. When the apparent fluidity is more than 1.0, the percolation curve shows modified Darcy flow characteristics, while when the apparent fluidity is less than 1.0, the percolation curve is a "concaveup" non-Darcy percolation curve; 3) Oil-water two-phase relative permeability is affected by core permeability, fluid viscosity, apparent fluidity, and injection drive force; 4) The oil saturation of lowpermeability sandstone reservoirs is mostly within $35 \%-60 \%$, and the oil saturation also has a good positive correlation with the permeability and apparent fluidity.
\end{abstract}

Key words: Non-Darcy flow, relative permeability, oil saturation, low-permeability sandstone

\section{Introduction}

Actually, low-permeability sandstone is a relatively indistinct concept, which has not been strictly and precisely defined internationally yet. Berg (1975) suggested that the upper limit of low-permeability sandstone was $1 \times 10^{-3}$ $\mu \mathrm{m}^{2}-10 \times 10^{-3} \mu \mathrm{m}^{2}$. The classification standards for reservoir properties of clastic rock and non-clastic rock issued by the Chinese National Committee on Mineral Reserves define a reservoir with porosity between $10 \%$ and $15 \%$ and permeability between $5 \times 10^{-3} \mu \mathrm{m}^{2}$ and $50 \times 10^{-3} \mu^{2}$ as lowporosity and low-permeability reservoir, while that with porosity less than $10 \%$ and permeability less than $5 \times 10^{-3} \mu^{2}$ as super-low-porosity and super-low-permeability reservoir (Li, 1997).

*Corresponding author. email: zengjh@cup.edu.cn Received September 15, 2009
The oil and gas resources preserved in low-permeability sandstone are very abundant and are extensively distributed all over the world. They can be found in almost every oilproducing country. A big quantity of low-permeability sandstone deep-basin gas reservoirs were discovered in the Los Angeles Basin and Powder River Basin of the US, Carpathians, Krasnodar, Urals-Volga and West Siberian oil province of the former Soviet Union, and the Alberta Basin in the west of Canada (Surdam, 1995; 1996; Law, 2002; Ayers, 2002; Williams et al, 1998). In China, low-permeability sandstone reservoirs are common in almost all the oil and gas bearing basins, especially in the Ordos, Sichuan, Junggar, Tarim and Songliao Basins. According to the statistics of Jiang et al (2004), the petroleum resources in China amount to $940 \times 10^{8} \mathrm{t}$, of which $210.7 \times 10^{8} \mathrm{t}(22.41 \%)$ occur in low-permeability sandstone. Among the newly increased proven reserves in recent years, low-permeability reservoir hydrocarbon reaches $70 \%$, and the proportion is increasing. 
Low-permeability sandstone reservoirs have many different characteristics from conventional reservoirs. They are mainly distributed in the slope and syncline locations in basins without a definite trap boundary or caprock. Their reservoir rocks have low porosity and permeability or super low porosity and permeability (porosity less than $10 \%$ and

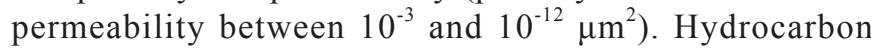
resources are extensive but unevenly distributed inside or near the source area with no migration or primary migration due to limited buoyancy effect. Under abnormal pressure (high or low pressure) and with no clear gravitational differentiation, oil-gas-water distribution is complex and hydrocarbon is locally accumulated with relatively low oil (gas) saturation (Law and Curtis, 2002; Ayers, 2002; Williams et al, 1998; Pang et al, 2002; Zhao et al, 2004; Zhang et al, 2006; Min et al, 1998; Wu et al, 2007; Yang et al, 2003; Zhang and Wang, 2003).

It is very difficult to explain the hydrocarbon distribution rule of low-permeability reservoir by conventional petroleum geology theory, which is probably related to the special pore characteristics and pore structure of low-permeability rocks and the special migration and accumulation mechanisms of the hydrocarbon in this kind of pores.

In 1856, a French engineer, Darcy, suggested that, fluid percolation characteristics in porous media could be described with what would later be called Darcy's Law, which argued that the pressure loss was totally determined by viscous force. In the middle period of the 20th century, the research results indicated that the flow of water and oil in soil, sand, porous ceramics, and underground reservoirs did not follow Darcy's Law but behaved as a non-Darcy fluid, i.e., the percolation velocity and pressure gradient in the percolation movement expression showed non-linear relation, and a threshold pressure gradient existed (Miller and Low, 1963; Olsen, 1965). During the last twenty years, with the extensive exploitation of low-permeability reservoirs, many scholars have studied by simulation experiments the percolation characteristics of oil and gas in low-permeability sandstone during the exploitation process, namely the water displacing oil process from the viewpoint of hydrocarbon production. The research results indicated that, fluid migration in lowpermeability reservoirs presented non-linear characteristics, and the oil-gas-water percolation behaved as a non-Darcy flow with a threshold pressure gradient (Yan et al, 1990; Li et al, 2003; Ruan and He, 1999a; 1999b; Yao and Ge, 2000; 2003; Deng et al, 2000; Cheng and Chen, 1998; Ren et al, 1997; Xue et al, 2001; Huang, 1997; 1998; Deng and Liu, 2006; Han et al, 2004; Huang et al, 2005; Wang et al, 2004; Pascal and Pascal, 1997; Prada and Civan, 1999; Li, 1997; Feng, 1986; Civan, 2000; Merrikh and Mohamad, 2002; Soni, 1978). However, the research has mainly been about the nonDarcy percolation characteristics of water-displacing-oil from the viewpoint of single-phase percolation or hydrocarbon exploitation, while few people have studied the nonDarcy flow characteristics and the distribution of oil (gas) saturation in low-permeability sandstone from the viewpoint of hydrocarbon accumulation (oil/gas displacing water). Based on simulation experiments, we firstly determined the
non-Darcy percolation curve of low-permeability sandstone (oil displacing water) and discussed its influencing factors; then, studied the value and change of relative permeability that was the key parameter characterizing the migration and accumulation of oil and gas in low-permeability sandstone; and finally, discussed the value, growth process and influencing factors of oil saturation of low-permeability sandstone under oil/water phase non-Darcy flow condition.

\section{Non-Darcy characteristics of oil migration in low-permeability sandstones}

\subsection{Experimental methods and equipment}

The cores in the experiments were from the Yaol Member in the Gulong Sag, Songliao Basin. First, the cores were washed free of oil with a solvent, and then dried. Second, the length, diameter, porosity and permeability of the cores were measured. Finally, the cores were vacuum-pumped and saturated with water (Zhu et al, 2009). We added kerosene to crude oil to obtain experimental oil with different viscosities. The salinity of salt water is $6.0 \mathrm{~g} / \mathrm{L}$ and viscosity is 1.005 $\mathrm{mPa} \cdot \mathrm{s}$. The experimental temperatures were set at $70^{\circ} \mathrm{C}$ and $90^{\circ} \mathrm{C}$ (Table 1$)$.

The experimental equipment was composed of five parts, namely, fluid injection system, fluid displacement system, temperature and pressure control system, fluid measurement system, and data acquisition and processing system, with the experimental procedure shown in Fig. 1.

We used the constant pressure method with simulated oil as the flowing medium, and conducted oil-displacing-water percolation experiments to study oil migration characteristics of low-permeability sandstone during reservoir formation. The experiment started from the minimum displacement pressure determined by the lowest flow velocity at the export end of cores, and when the export flow velocity ranged from $0 \mathrm{~mL} / \mathrm{min}$ to $0.01 \mathrm{~mL} / \mathrm{min}$, the pressure could be regarded as the minimum displacing pressure. The pressure of the injecting pump was set in advance and was kept constant. The pressure differences between the import end and the export end of the rock sample at the flow velocity were measured with a sensitive pressure sensor, and the fluid velocity at the export end was accurately metered with an automatic fluid meter. The pressure difference and export velocity values were recorded every preset time interval (commonly 3-5 $\min$ ). When the continuously recorded export velocity values stabilized around a specific value (the difference between two successive measured values was less than $2 \%$ continuously), it was considered that under a specific constant displacing pressure difference, the percolation velocity at the export end of the rock sample reached a stable state. Then the balanced pressure difference and export velocity values at such flow velocity were recorded. We gradually increased the injecting pressure, and when the pressure was stable, we recorded the corresponding pressure difference and flow velocity values. In the similar way, we selected ten different fluid injecting pressures and recorded relevant data respectively until the export end had no water flowing out. 
Table 1 Parameters in the simulation experiments

\begin{tabular}{|c|c|c|c|c|c|c|c|}
\hline Core number & $\begin{array}{c}\text { Length } \\
\mathrm{cm}\end{array}$ & $\begin{array}{l}\text { Diameter } \\
\mathrm{cm}\end{array}$ & $\begin{array}{c}\text { Porosity } \\
\%\end{array}$ & $\begin{array}{c}\text { Permeability } \\
10^{-3} \mu \mathrm{m}^{2}\end{array}$ & $\begin{array}{c}\text { Fluid viscosity } \\
\mathrm{mPa} \cdot \mathrm{s}\end{array}$ & Apparent fluidity & $\begin{array}{l}\text { Threshold pressure } \\
\text { gradient, } \mathrm{MPa} / \mathrm{cm}\end{array}$ \\
\hline 75 & 5.73 & 2.546 & 10.79 & 0.28 & 7.2 & 0.0389 & 0.1983 \\
\hline 63 & 5.7 & 2.5 & 17.95 & 0.62 & 7.2 & 0.0861 & 0.0764 \\
\hline $79-2$ & 5.84 & 2.54 & 12.71 & 0.85 & 7.2 & 0.1181 & 0.0538 \\
\hline 42 & 5.76 & 2.496 & 16.56 & 1.01 & 7.2 & 0.1403 & 0.0785 \\
\hline $82-2$ & 5.23 & 2.542 & 18.92 & 4.53 & 7.2 & 0.6292 & 0.0216 \\
\hline 124 & 5.77 & 2.51 & 20.81 & 5.33 & 7.2 & 0.7403 & 0.0138 \\
\hline 119 & 6.038 & 2.514 & 15.72 & 7.86 & 7.2 & 1.0917 & 0.0200 \\
\hline 105 & 5.385 & 2.52 & 21.7 & 12.55 & 7.2 & 1.7431 & 0.0286 \\
\hline 97 & 7.44 & 2.514 & 19.48 & 21.1 & 7.2 & 2.9306 & 0.0100 \\
\hline 45 & 5.73 & 2.52 & 13.54 & 0.82 & 19.2 & 0.0429 & 0.1365 \\
\hline 112 & 5.66 & 2.51 & 21.74 & 1.42 & 19.2 & 0.0740 & 0.1056 \\
\hline 46 & 5.82 & 2.52 & 16.44 & 4.69 & 19.2 & 0.2443 & 0.0456 \\
\hline $80-2$ & 7.62 & 2.538 & 16.33 & 7.62 & 19.2 & 0.3969 & 0.0254 \\
\hline
\end{tabular}

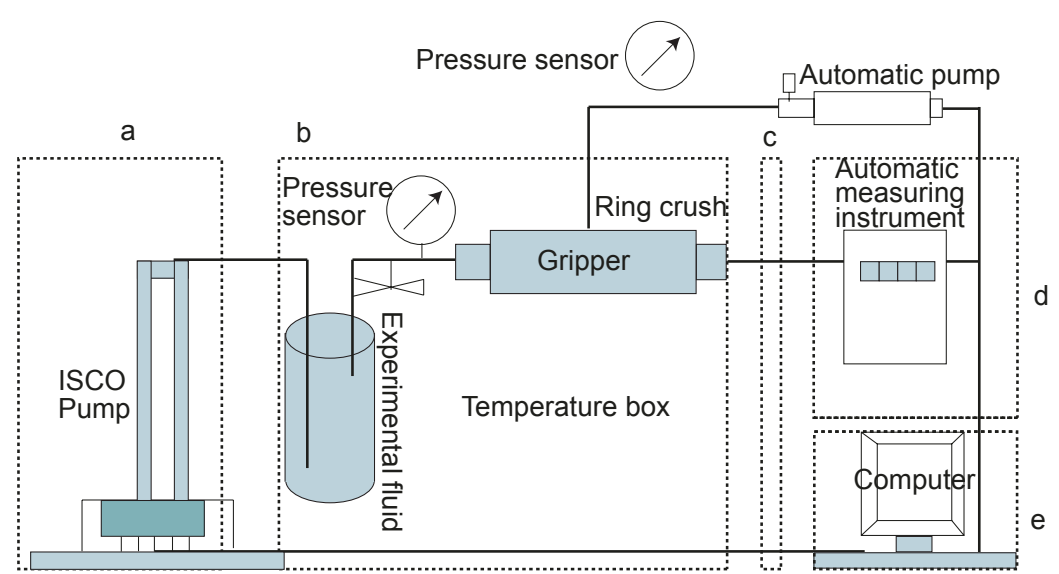

a: fluid injection system; b: fluid displacement system; c: temperature and pressure control system; d: fluid measurement system; e: data acquisition and processing system

Fig. 1 Flow chart of the simulation experiment

\subsection{Non-Darcy percolation curve for oil migration (oil displacing water)}

\subsubsection{Types of non-Darcy percolation curve for oi migration (oil displacing water)}

Results of the simulation experiments indicated that nonDarcy percolation curves for oil migration (oil displacing water) of low-permeability sandstone were mainly of two types (Fig. 2 and Fig. 3).

(1) Modified non-Darcy percolation curve

For the modified non-Darcy type of percolation curve, in the range of experimental flow velocity, the pressure gradient and flow velocity show a linear relation, and there is no nonlinear part of the curve. However, it is different from the Darcy percolation curve in that the straight line extrapolated in the opposite direction does not pass through the origin of coordinates. Fig. 2 shows modified non-Darcy percolation curves of simulated oil with fluid viscosity of $7.2 \mathrm{mPa} \cdot \mathrm{s}$ $\left(90^{\circ} \mathrm{C}\right.$ ) in core 119 (permeability: $\left.7.86 \times 10^{-3} \mu \mathrm{m}^{2}\right)$, core 105 (permeability: $12.55 \times 10^{-3} \mu \mathrm{m}^{2}$ ) and core 97 (permeability: $\left.21.10 \times 10^{-3} \mu \mathrm{m}^{2}\right)$, respectively.

(2) Concave-up non-Darcy percolation curve

In the range of experimental flow velocity, this type of percolation curve consists of two gentle transition segments: 


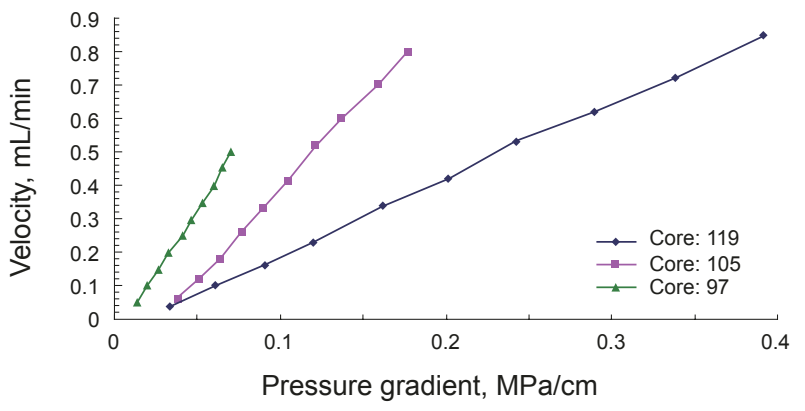

Fig. 2 Modified percolation curves of oil-water two-phase flow in low-permeability sandstone

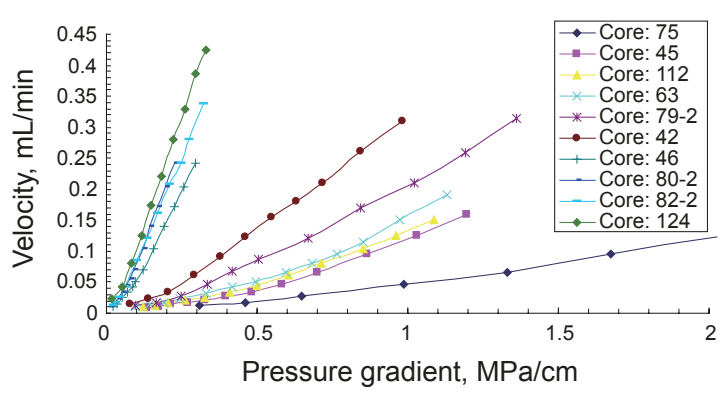

Fig. 3 Concave-up non-Darcy percolation curves of oil-water two-phase flow in low-permeability sandstone

concave-up non-linear percolation curve at relatively low percolation velocity and pseudo-linear percolation curve at relatively high percolation velocity. As shown in Fig. 3, the percolation curves are characterized by low-velocity nonDarcy percolation with a threshold pressure gradient, and the extension of the straight line segment has an intercept on the pressure gradient axis, which is the pseudo threshold pressure gradient. The curve segment is generally concave to the flow velocity axis. With an increase of the percolation velocity, the curve shows a transition from non-linear to linear.

\subsubsection{Threshold pressure gradient}

One of the largest differences between non-Darcy percolation and Darcy percolation is the existence of a threshold pressure gradient (Miller and Low, 1963; Yan et al, 1990; Cheng and Chen, 1998; Ruan et al, 1998; Wu et al, 1999; Chen et al, 2003; Song and Liu, 2001; Yao and Ge, 2003; Li et al, 2005; 2007). Results of the simulation experiments indicate that when oil accumulates and forms a reservoir (oil/water two-phase migration) in low-permeability sandstone, the threshold pressure gradient for non-Darcy flow has a minimum value of $0.010 \mathrm{MPa} / \mathrm{cm}$ and a maximum value of $2.9306 \mathrm{MPa} / \mathrm{cm}$ (Table 1).

Though the threshold pressure gradient shows a relatively poor correlation with porosity, it presents a relatively good negative correlation with permeability $\left(y=0.079 x^{-0.6205}\right.$, $R^{2}=0.8072$ ). With the increase of sandstone permeability, the threshold pressure gradient decreases in a power function (Fig. 4). The reason might be that, compared with porosity, permeability can better reflect the permeable performance of rock and migration capability of fluid, thus leading to very good correlation between threshold pressure gradient and permeability.

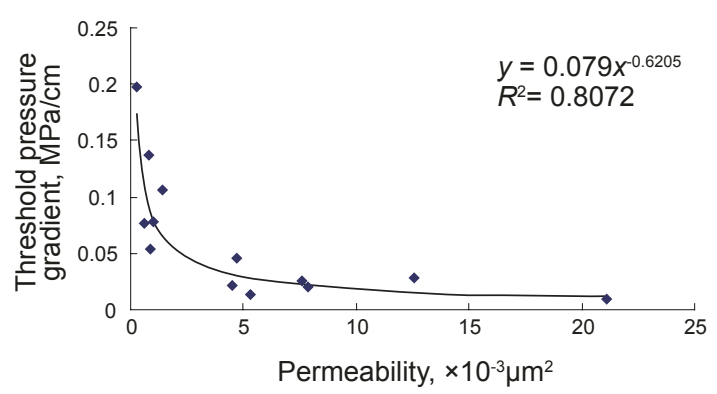

Fig. 4 Relation between threshold pressure gradient and permeability

Since the migration of oil in low-permeability sandstone is actually the result of physical interaction between lowpermeability sandstone and fluid, threshold pressure gradient is not only related to the properties of the low-permeability sandstone, but also related to the properties of the fluid. Therefore, it is necessary to discuss the relation between threshold pressure gradient and apparent fluidity which is a parameter reflecting physical interaction between sandstone and fluid (ratio of rock permeability to fluid viscosity, $\mathrm{k} / \mu$ ). Fig. 5 shows that threshold pressure gradient is well negatively correlated with apparent fluidity $(y=0.0196$ $\left.x^{-0.6078}, R^{2}=0.8824\right)$. With an increase of apparent fluidity, the threshold pressure gradient decreases in a power function, showing a better correlation than that between threshold pressure gradient and permeability, which indicates that apparent fluidity can better reflect the changes of threshold pressure gradient during oil migration in low-permeability sandstone.

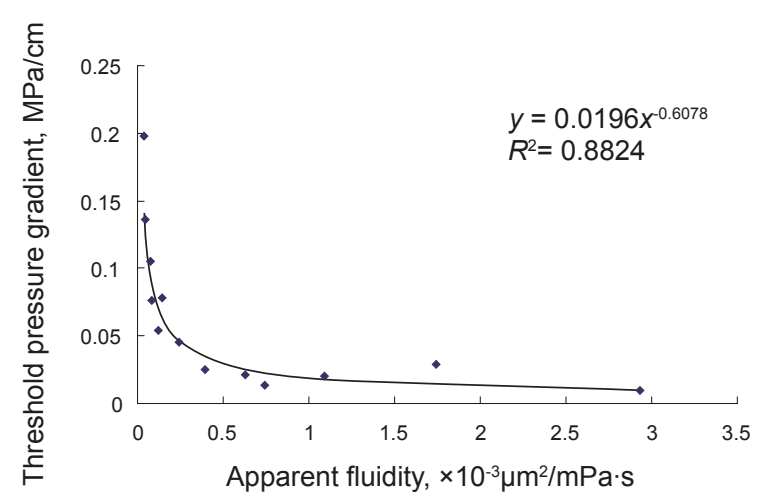

Fig. 5 Relation between threshold pressure gradient and apparent fluidity

\subsection{Influencing factors of oil non-Darcy flow in low- permeability sandstone}

Similar to the influencing factors of oil, gas, and water single-phase flow in low-permeability sandstone, the results of percolation experiments of oil-water two-phase migration indicate that fluid and sandstone properties, and interaction between fluid and rock jointly influence the percolation characteristics of oil-water two-phase migration in lowpermeability sandstone. 


\subsubsection{Fluid viscosity $(\mu)$}

Fluid viscosity is a main factor influencing percolation characteristics of oil-water two-phase migration in lowpermeability sandstone. Results of the simulation experiments show that, when the core permeabilities are almost the same but fluid viscosities are different, the percolation curve characteristics are also different. The higher the fluid viscosity, the more inclined to the pressure gradient axis the percolation curve, and the longer the non-linear segment of the curve. The smaller the curvature, the bigger the intercept of straight line segment on the pressure gradient axis, and the more obvious the non-Darcy phenomenon (Fig. 6). To reach the same flow rate, a fluid with higher viscosity needs a higher pressure gradient. As shown in Table 2 and Fig. 6, core 79-2 (permeability: $0.85 \times 10^{-3} \mu \mathrm{m}^{2}$ ) and core 45 (permeability: $0.82 \times 10^{-3} \mathrm{~mm}^{2}$ ) have similar permeabilities, while with the increase of fluid viscosity from $7.2 \mathrm{mPa} \cdot \mathrm{s}\left(90^{\circ} \mathrm{C}\right)$ to 19.2 $\mathrm{mPa} \cdot \mathrm{s}\left(70^{\circ} \mathrm{C}\right)$, the intercept of the percolation curve on the pressure gradient axis increases from $0.2476 \mathrm{MPa} / \mathrm{cm}$ to $0.3621 \mathrm{MPa} / \mathrm{cm}$. Likewise, core 42 (permeability: $1.01 \times 10^{-3}$ $\mu \mathrm{m}^{2}$ ) and core 112 (permeability: $1.42 \times 10^{-3} \mu \mathrm{m}^{2}$ ) have similar permeabilities, while with the increase of fluid viscosity from $7.2 \mathrm{mPa} \cdot \mathrm{s}\left(90^{\circ} \mathrm{C}\right)$ to $19.2 \mathrm{mPa} \cdot \mathrm{s}\left(70^{\circ} \mathrm{C}\right)$, the intercept of the percolation curve on the pressure gradient axis increases from $0.1700 \mathrm{MPa} / \mathrm{cm}$ to $0.2847 \mathrm{MPa} / \mathrm{cm}$.

Table 2 Intercepts of oil-water two-phase percolation curve on the pressure gradient axis

\begin{tabular}{cccccc}
\hline Core number & $\begin{array}{c}\text { Porosity } \\
\%\end{array}$ & $\begin{array}{c}\text { Permeability } \\
\times 10^{-3} \mu \mathrm{m}^{2}\end{array}$ & $\begin{array}{c}\text { Fluid viscosity } \\
\mathrm{mPa} \cdot \mathrm{s}\end{array}$ & Linear equation & $\begin{array}{c}\text { Intercept } \\
\mathrm{MPa} / \mathrm{cm}\end{array}$ \\
\hline $79-2$ & 12.71 & 0.85 & 7.2 & $y=0.2835 x^{-0.0702}$ & 0.2476 \\
45 & 13.54 & 0.82 & 19.2 & $y=0.1917 x^{-0.0694}$ & 0.3621 \\
42 & 16.56 & 1.01 & 7.2 & $y=0.3825 x^{-0.0650}$ & 0.1700 \\
112 & 21.74 & 1.42 & 19.2 & $y=0.1869 x^{-0.0532}$ & 0.2847 \\
\hline
\end{tabular}
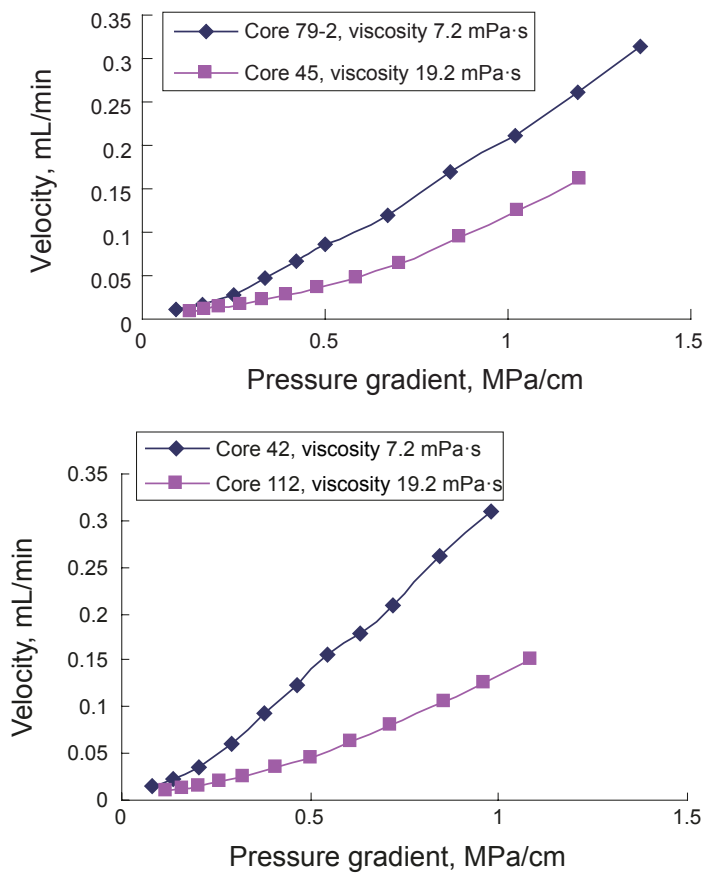

Fig. 6 Percolation curves with different fluid viscosity

\subsubsection{Porosity and permeability of low-permeability sandstones}

Results of the simulation experiments show that, under the same fluid viscosity condition, the percolation curve of oil-water two-phase migration has a complicated relation with porosity, but it is well related with permeability (Fig. 7 and Fig. 8), which is represented as follows:

1) The curve shape and position change regularly with permeability. The curve is mainly modified non-Darcy percolation when the sandstone permeability is relatively high, while it is mainly concave-up non-Darcy percolation when the sandstone permeability is relatively low.

2) The lower the permeability, the more inclined the percolation curve is to the pressure gradient axis, and the

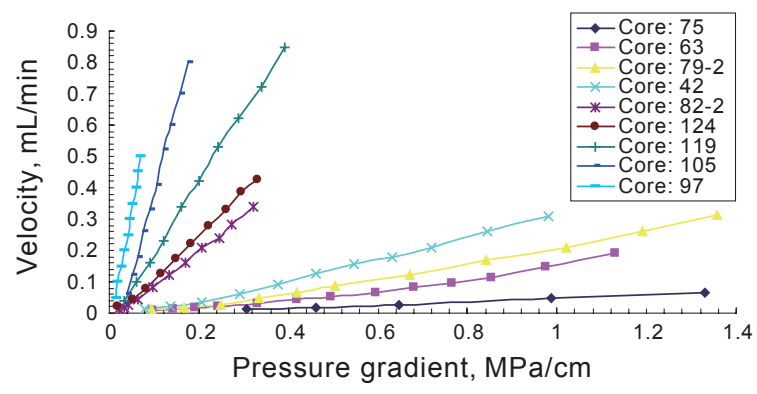

Fig. 7 Percolation curves of oil-water two-phase flow in low-permeability sandstone (viscosity: $7.2 \mathrm{mPa} \cdot \mathrm{s}$ )

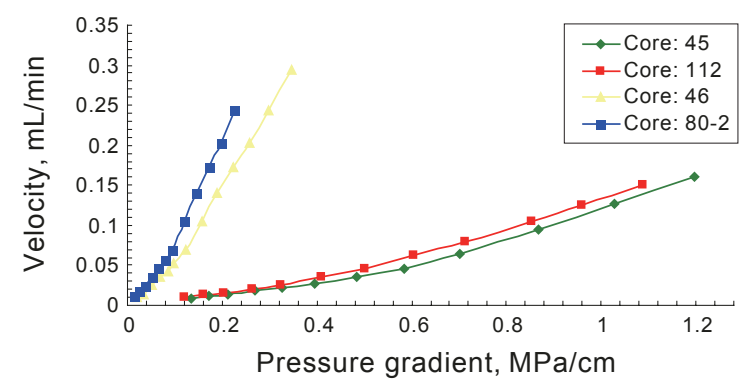

Fig. 8 Percolation curves of oil-water two-phase flow in low-permeability sandstone (viscosity: $19.2 \mathrm{mPa} \cdot \mathrm{s}$ ) 
lower the slope of straight line segment.

3) With a decrease of permeability, the non-linear segment of the curve extends longer, the curvature decreases, and the intercept of the straight line segment on the pressure gradient axis increases. The higher the threshold pressure gradient, the more obvious the non-Darcy phenomenon. As shown in Fig. 8 and Table 3, under the same fluid viscosity condition (19.2 $\mathrm{mPa} \cdot \mathrm{s}$ ), core $80-2$ (permeability: $7.62 \times 10^{-3} \mu \mathrm{m}^{2}$ ) has the highest permeability, and the intercept of its percolation curve on the pressure gradient axis is the minimum value 0.0401 $\mathrm{MPa} / \mathrm{cm}$. When the permeability decreases to $4.69 \times 10^{-3} \mu \mathrm{m}^{2}$ (core 46), the intercept increases to $0.0554 \mathrm{MPa} / \mathrm{cm}$; when the permeability decreases to $1.42 \times 10^{-3} \mu^{2}$ (core 112 ), the intercept increases to $0.2847 \mathrm{MPa} / \mathrm{cm}$; when the permeability decreases to $0.82 \times 10^{-3} \mu^{2}$ (core 45 ), the intercept increases to $0.3621 \mathrm{MPa} / \mathrm{cm}$.

Table 3 Intercepts of oil-water two-phase percolation curve on the pressure gradient axis

\begin{tabular}{cccccc}
\hline Core number & $\begin{array}{c}\text { Porosity } \\
\%\end{array}$ & $\begin{array}{c}\text { Permeability } \\
\times 10^{-3} \mu \mathrm{m}^{2}\end{array}$ & $\begin{array}{c}\text { Fluid viscosity } \\
\mathrm{mPa} \cdot \mathrm{s}\end{array}$ & $\begin{array}{c}\text { Equation of straight } \\
\text { line segment }\end{array}$ & $\begin{array}{c}\text { Intercept } \\
\mathrm{MPa} / \mathrm{cm}\end{array}$ \\
\hline 45 & 13.54 & 0.82 & 19.2 & $y=0.1917 x^{-0.0694}$ & 0.3621 \\
112 & 21.74 & 1.42 & 19.2 & $y=0.1869 x^{-0.0532}$ & 0.2847 \\
46 & 16.44 & 4.69 & 19.2 & $y=1.0168 x^{-0.0564}$ & 0.0554 \\
$80-2$ & 16.33 & 7.62 & 19.2 & $y=1.3047 x^{-0.0523}$ & 0.0401 \\
\hline
\end{tabular}

\subsubsection{Apparent fluidity $(\mathrm{k} / \mu)$}

Apparent fluidity is the ratio of the rock permeability to the fluid viscosity $(\mathrm{k} / \mu)$. Since oil migration in lowpermeability sandstone is the result of physical interaction between sandstone and fluid, it is necessary to discuss the influence of apparent fluidity on the percolation characteristics of oil-water two-phase migration. Results of simulation experiments indicate that, when the apparent fluidity is more than 1 , the percolation curve is characterized by modified Darcy flow, and the relation curve of pressure gradient and flow velocity is linear with no non-linear segment. The extrapolated straight line does not pass through the origin of the coordinates. The higher the apparent fluidity, the more inclined to the flow velocity axis the straight line. It is indicated that under the same pressure gradient, the larger the increase of flow velocity, the more easily percolation occurs (Fig. 9). When the apparent fluidity is less than 1, the curve is characterized by typical concave-up non-Darcy percolation, whose shape and position change regularly with changes in apparent fluidity. The lower the apparent fluidity, the more inclined the percolation curve is to the pressure gradient axis, and the longer the non-linear segment of the curve extends. The smaller the curvature, the lower the slope of straight line segment of the curve, and the larger the intercept of straight line segment on the pressure gradient axis. Thus, the higher the threshold pressure gradient, the more obvious the nonDarcy phenomenon (Fig. 10).

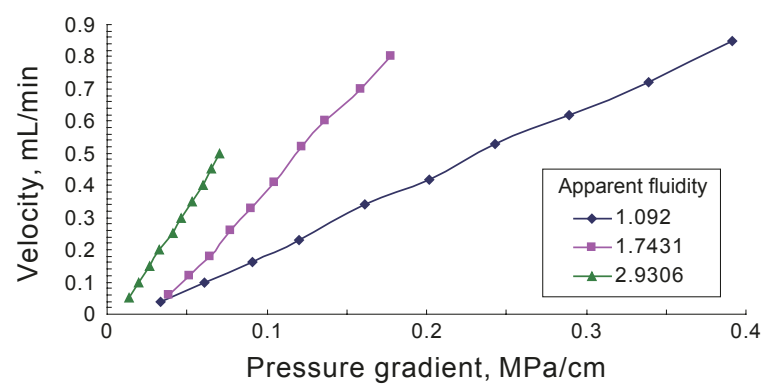

Fig. 9 Percolation curves of oil-water two-phase migration in low-permeability sandstone (apparent fluidity $>1$ )

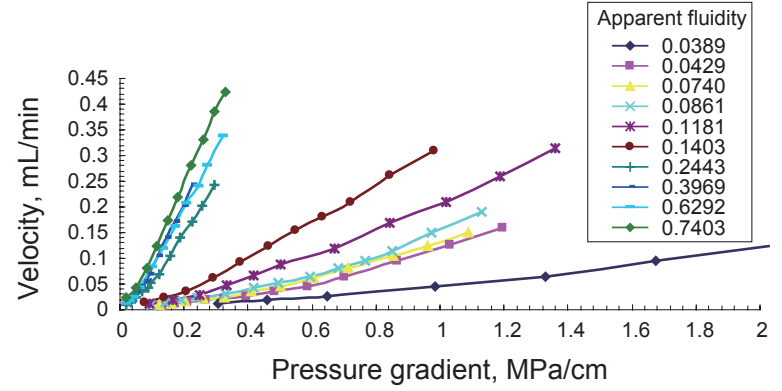

Fig. 10 Percolation curves of oil-water two-phase migration in lowpermeability sandstone (apparent fluidity $<1$ )

\section{Oil-water relative permeability curve and its influencing factors}

The formation of a low-permeability sandstone reservoir is a process of crude oil displacing formation water, which is characterized by oil-water two-phase migration. The oilwater relative permeability has an important influence on oil migration and accumulation, so we need determine the oil-water relative permeability and the factors influencing it for studying the formation of low-permeability sandstone reservoirs.

Currently, there are many methods to measure twophase relative permeability. Among conventional unstable methods, the JBN analysis method (Johnson et al, 1959), based on Darcy's Law, is the most widely used. However, for low-permeability sandstones, the percolation of fluid shows non-Darcy characteristics and there is a threshold pressure gradient, so the JBN method is obviously not applicable. Based on the low-permeability non-Darcy percolation theory, previous researchers derived calculation formulae of oil-water relative permeability in consideration of threshold pressure gradient, and studied the characteristics and influencing factors of oil-water relative permeability curves of lowpermeability oil reservoirs under oil exploitation conditions 
(Zhang and Yin, 1999; Song and Liu, 2000; Lin and Shi, 2000; Deng et al, 2000; Jia et al, 2001; Cui et al, 2003; Wang et al, 2004; Ran et al, 2006; Dong et al, 2007; Luo et al, 2007; Hou et al, 2008). According to the calculation method of two-phase relative permeability during the production from low-permeability reservoir (water displacing oil) presented by Song and Liu (2000), we studied the oil-water relative permeability curve and its influencing factors in the process of reservoir formation (oil displacing water) through simulation experiments to better understand the characteristics of oil migration and accumulation in low-permeability sandstone.

On the contrary to the oil production process (water displacing oil), the reservoir formation process could be viewed as the migration and accumulation of oil in the reservoir, namely a process of oil displacing formation water. Therefore its oil-water relative permeability curve is obviously different from that of the oil development process (water displacing oil). The results of our simulation experiments show that the oil-water relative permeability curve of lowpermeability sandstone has unique characteristics. Commonflow region is the area where the relative permeability of both water and oil are not equal to zero in the oil-water relative permeability curve. Common-flow point is the point at which the relative permeability of water and oil are equal, and is the intersection point of oil and water relative permeability curves (Fig. 11-Fig. 13 and Table 4).

1) When the oil saturation rises, the water-phase relative permeability drops rapidly but the oil-phase relative permeability rises a little to a low value. The area where both oil and water flow is small, and the final oil saturation is low.

2) The water-phase relative permeability curve varies a lot in shape, including concave-up (Fig. 11), "S" shape (Fig. 12), and wavy (Fig. 13), which reflects the interactions between different fluids, those on phase interfaces between fluid and solid, and the variability and complexity of percolation states.

3) Core permeability has important influence on the oilwater relative permeability. The higher the core permeability, the larger the region in which both oil and water flow. Thus, the common-flow point moves to the right, and both final oilphase permeability and final oil saturation are high (Fig. 14).

4) The fluid viscosity also affects the oil-water relative permeability. The higher the fluid viscosity, the smaller the region where both oil and water flow. Thus, the common-flow point moves to the left, and both final oil-phase permeability and final oil saturation are low (Fig. 15).

5) The combined action of physical properties of the core and fluid viscosity (apparent fluidity) affect the relative permeability. The higher the apparent fluidity, the larger the

Table 4 Parameters of oil-water relative permeability curve

\begin{tabular}{|c|c|c|c|c|c|}
\hline Core number & $\begin{array}{l}\text { Permeability } \\
\quad \times 10^{-3} \mu^{2}\end{array}$ & $\begin{array}{l}\text { Fluid viscosity } \\
\qquad \mathrm{mPa} \cdot \mathrm{s}\end{array}$ & $\begin{array}{l}\text { Final oil saturation } \\
\%\end{array}$ & $\begin{array}{l}\text { Oil-phase relative } \\
\text { permeability at final } \\
\text { oil saturation }\end{array}$ & $\begin{array}{c}\text { Oil saturation at oil-water } \\
\text { intersection point } \\
\%\end{array}$ \\
\hline 75 & 0.28 & 7.2 & 39.15 & 0.1876 & 24.5 \\
\hline $79-2$ & 0.85 & 7.2 & 42.54 & 0.2248 & 28.3 \\
\hline 97 & 21.1 & 7.2 & 65.86 & 0.3577 & 47.0 \\
\hline 45 & 0.82 & 19.2 & 38.56 & 0.1835 & 27.5 \\
\hline
\end{tabular}

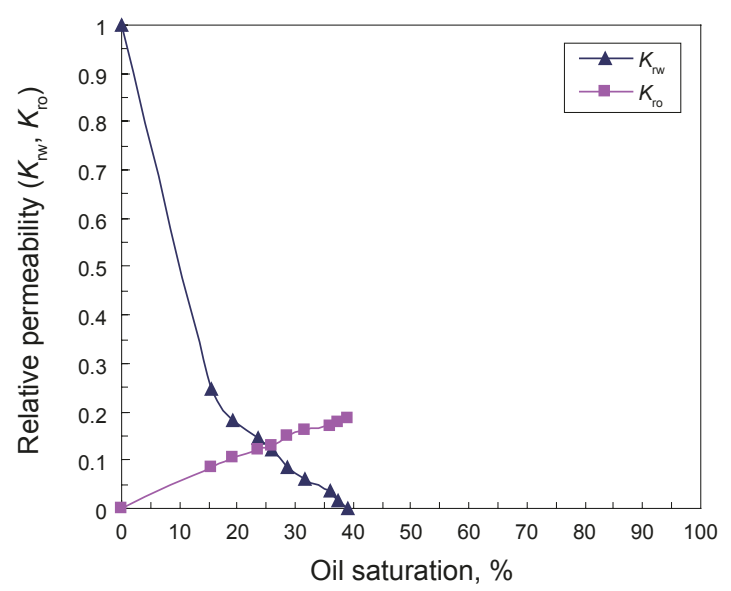

Fig. 11 Oil-water relative permeability of core 75

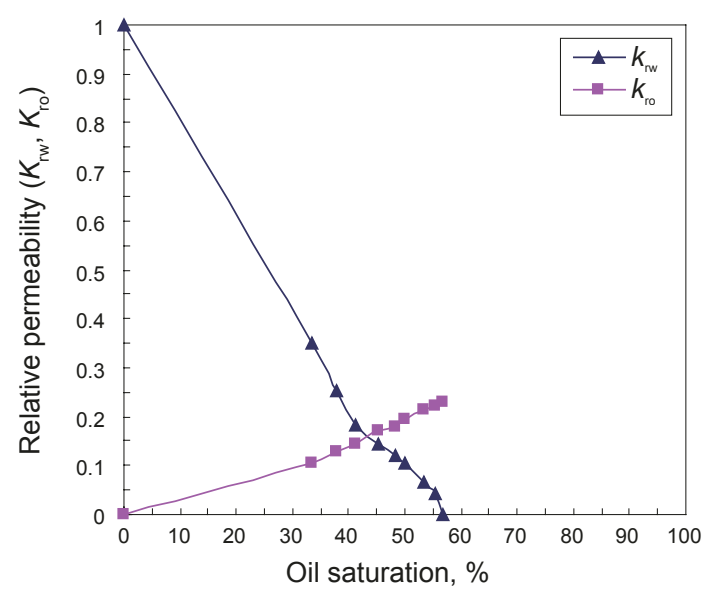

Fig. 12 Oil-water relative permeability of core 124 


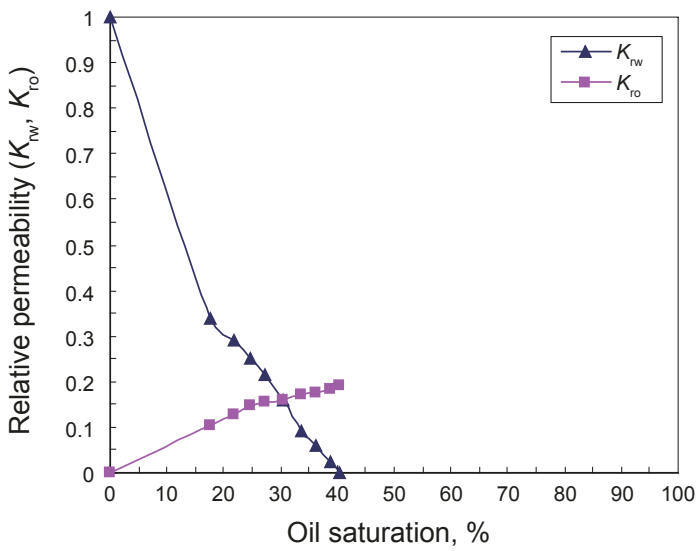

Fig. 13 Oil-water relative permeability of core 45

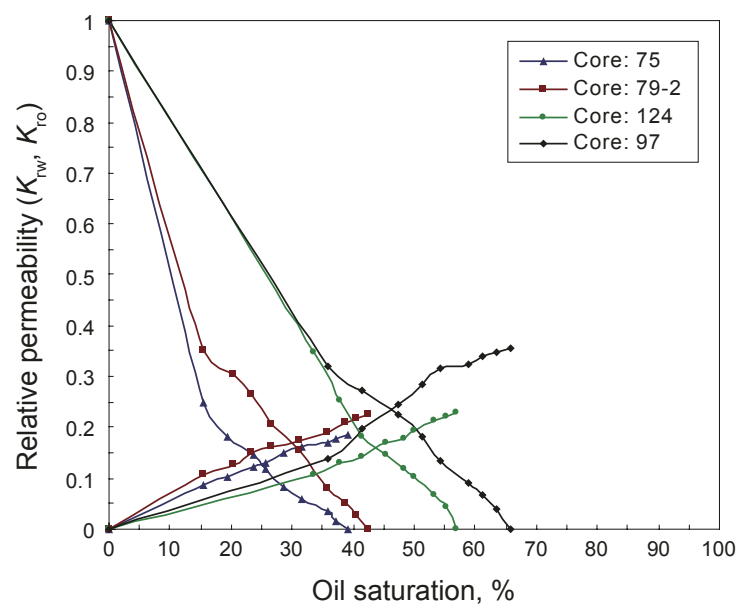

Fig. 14 Oil-water relative permeability with the same viscosity but different permeability

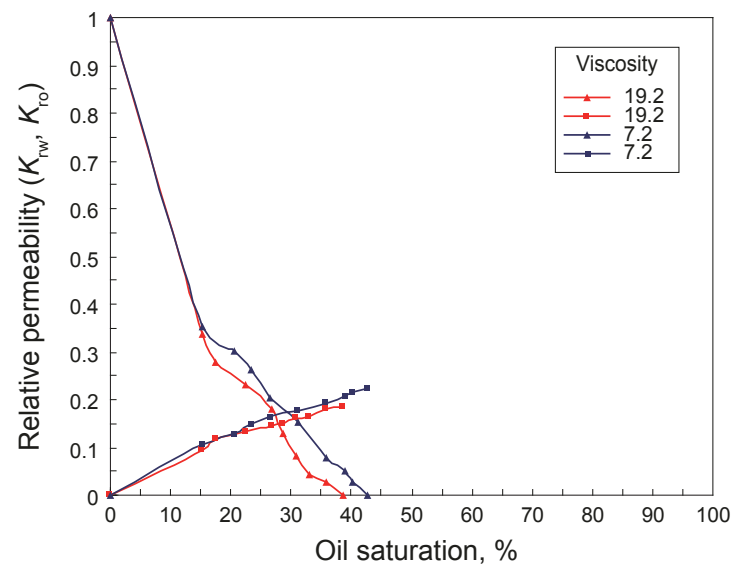

Fig. 15 Oil-water relative permeability with the same permeability but different viscosity

area where both oil and water flow. Thus, the common-flow point moves to the right, and both final oil-phase permeability and final oil saturation are high (Fig. 16).

6) The driving force of injection also has an important influence on the relative permeability curve, as shown in Fig. 17. The relative permeability curves of the same core with two different pressure gradients are put in one coordinate system. The larger the driving pressure gradient, the larger the decrease of the water-phase relative permeability and the larger the increase of oil-phase relative permeability. Thus, the common-flow point moves to the right, and both final oilphase permeability and final oil saturation are high.

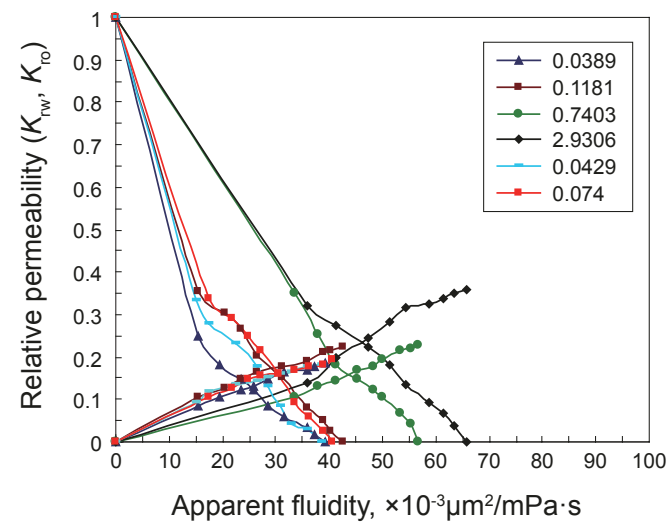

Fig. 16 Relative permeability with different apparent fluidities

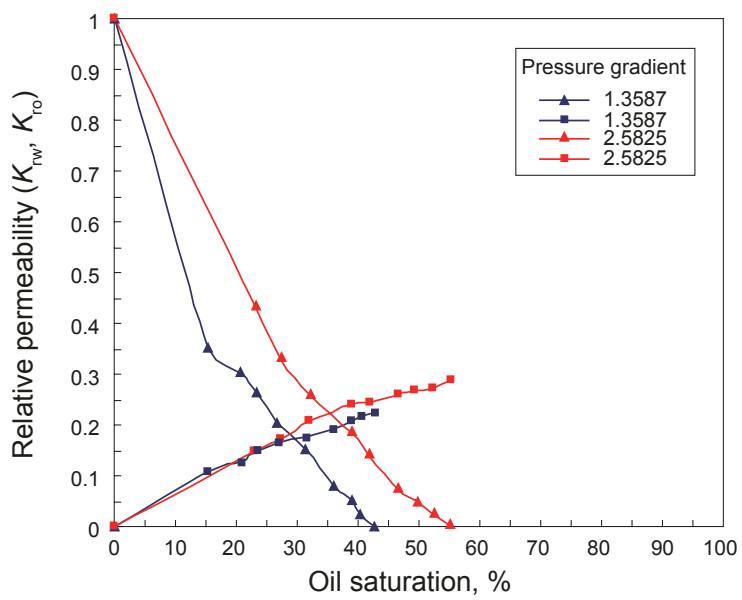

Fig. 17 Relative permeability with different pressure gradients (core 79-2)

\section{Oil saturation and the factors influencing it}

The processes of hydrocarbon accumulation and reservoir formation can be represented as the processes of oil displacing formation water and continuous increase of oil saturation in the reservoir under geological conditions.

\subsection{Oil saturation and its increasing process}

A lot of previous research indicates that low permeability hydrocarbon reservoirs are generally characterized by low oil saturation (mostly $<60 \%$ ) and high water saturation (generally 30\%-70\%) (Williams et al, 1998; Law and Curtis, 2002; Ayers, 2002; Pang et al, 2002; Yang et al, 2003; Zhao et al, 2004; Wu et al, 2007).

Results of our simulation experiments indicate that under the condition of maximum displacement pressure in the laboratory, the oil saturation of low-permeability sandstone is mostly in a range of $35 \%-60 \%$ (Fig. 18), basically consistent 
with previous research results. Besides, with the increase of the oil injection pressure gradient, the oil saturation in the core continuously increases, and the growth process can be classified into three stages: rapid growth stage, slow growth stage, and stable stage (Fig. 19).

The pressure gradient and oil saturation of the three stages are closely related to the core permeability. For example, for core 42 , the permeability is $1.01 \times 10^{-3} \mu^{2}$, the oil saturation in the rapid growth stage is $36.25 \%$, and the corresponding pressure gradient is $0.078 \mathrm{MPa} / \mathrm{cm}$. While for core 97 , the permeability is $21.1 \times 10^{-3} \mu \mathrm{m}^{2}$, the oil saturation in the rapid growth stage can reach $45.20 \%$, and the corresponding pressure gradient is only $0.013 \mathrm{MPa} / \mathrm{cm}$. In addition, there are obvious differences in oil saturation and pressure gradient in the slow growth stage and stable stage.

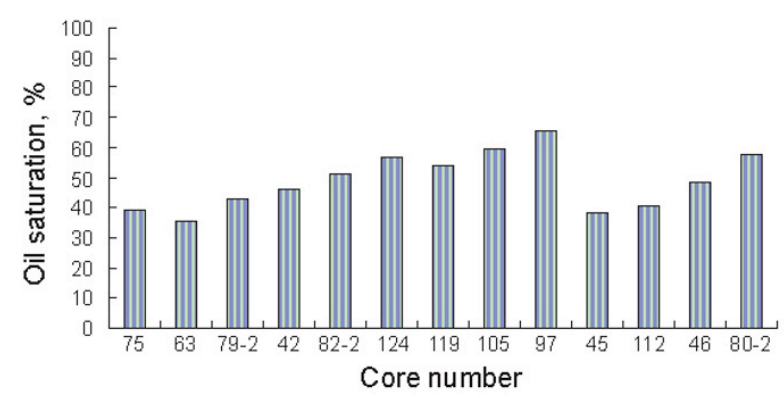

Fig. 18 Histogram of oil saturation in low-permeability sandstone

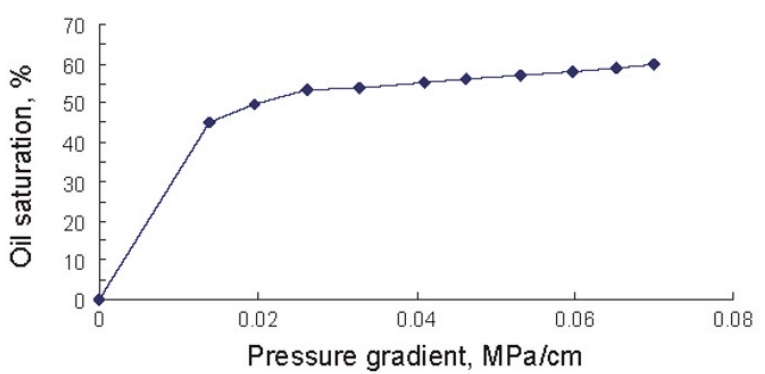

Fig. 19 Relation between oil saturation and pressure gradient of core 97

\subsection{Factors influencing oil saturation}

The increase of oil saturation of low-permeability sandstone is the process of crude oil displacing formation water, and also the process of comprehensive interaction of multiple factors, including reservoir physical properties, fluid viscosity, apparent fluidity, injection drive force, and injection proportion.

The relation between oil saturation of low-permeability sandstone and porosity is complicated, but the oil saturation shows a relatively good positive correlation with permeability and apparent fluidity, with correlation coefficients $R^{2}$ of 0.8796 and 0.8862 , respectively. With an increase of permeability and apparent fluidity, the oil saturation increases in a power function (Fig. 20 and Fig. 21).

Oil saturation of low-permeability sandstone is closely related to the injection drive force (pressure gradient). The

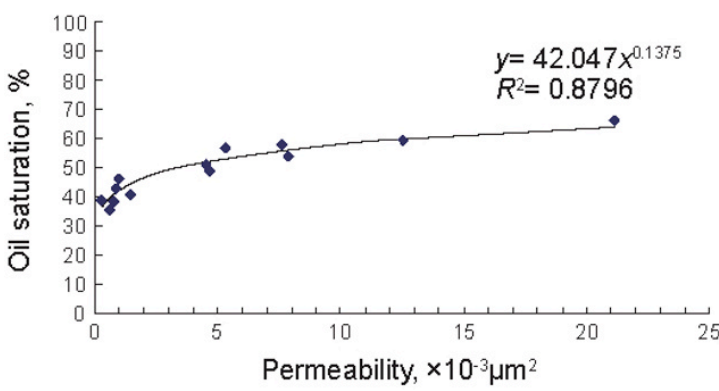

Fig. 20 Relation between oil saturation and permeability of low-perm eability sandstone

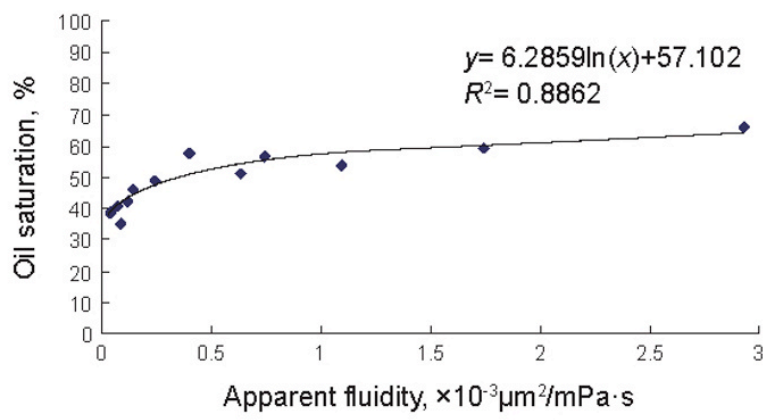

Fig. 21 Relation between oil saturation and apparent fluidity of low-permeability sandstone

larger the injection drive force (pressure gradient), the higher the oil saturation. For example, for core 63 with permeability of $0.62 \times 10^{-3} \mu^{2}$, in the first experiment, the final pressure gradient is $0.7615 \mathrm{MPa} / \mathrm{cm}$ and its final oil saturation is $38.28 \%$; while in the third experiment, the final pressure gradient increases to $1.1293 \mathrm{MPa} / \mathrm{cm}$ and its final oil saturation increases to $50.45 \%$. Therefore, the injection drive force is the main factor affecting oil saturation of low-permeability sandstone, and even for very compact sandstones with relatively poor physical properties, as long as the injection drive force is large enough, oil saturation can increase.

\section{Conclusions}

1) Oil migration (oil displacing water) in low-permeability sandstone shows non-Darcy percolation characteristics, and the percolation curves are mainly modified non-Darcy percolation and concave-up non-Darcy percolation curves.

2) During the formation of an oil reservoir (oil-water two-phase migration) in low-permeability sandstone, there is a threshold pressure gradient, with minimum value of $0.0100 \mathrm{MPa} / \mathrm{cm}$ and maximum value of $2.9306 \mathrm{MPa} / \mathrm{cm}$. The threshold pressure gradient shows a poor correlation with porosity but a good negative correlation with permeability and apparent fluidity, with the correlation equation and correlation coefficient of $y=0.079 x^{-0.6205}, R^{2}=0.8072$ and $y=0.0196 x^{-0.6078}$, $R^{2}=0.8824$, respectively.

3) The main factor influencing non-Darcy oil flow in low-permeability sandstone is apparent fluidity. The lower the apparent fluidity, the nearer the percolation curve to the pressure gradient axis, the lower the slope of the linear 
segment, the longer the extension of the non-linear segment, and the smaller the curvature. The bigger the intercept of the linear segment on the pressure gradient axis, the higher the threshold pressure gradient, and the more obvious the non-Darcy phenomenon. When the apparent fluidity is more than 1.0, the percolation curve shows modified Darcy flow characteristics; while when the apparent fluidity is less than 1.0, the percolation curve shows concave-up non-Darcy percolation characteristics.

4) For the oil-water relative permeability curve, when the oil saturation rises, the water-phase relative permeability drops rapidly but the oil-phase relative permeability rises a little to a low value. The region where both oil and water flow is small, and the final oil saturation is low. The core permeability, fluid viscosity, apparent fluidity, and injection drive force affect the oil-water relative permeability significantly. The higher the core permeability, the larger the decrease of water-phase relative permeability and the increase of oil-phase relative permeability. Thus, the oil-water common-flow region becomes larger, and the common-flow point moves to the right. Both final oil-phase permeability and final oil saturation are high. The influencing factors of apparent fluidity and driving pressure gradient are similar to those of core permeability.

5) The oil saturation of low-permeability hydrocarbon reservoirs is mostly within the range of $35 \%-60 \%$, and the growth of oil saturation undergoes three stages: rapid growth stage, slow growth stage, and stable stage. The oil saturation of low-permeability sandstone shows a good positive correlation with permeability and apparent fluidity, and with increase of injection drive force, the oil saturation also increases.

\section{Acknowledgements}

This research was financially supported by the National Natural Science Foundation Project (No.40772088) and the National Basic Research Program ("973” Program, Grant No. 2006CB202305).

\section{References}

Ayers Jr W B. Coalbed gas systems, resources, and production and a review of contrasting cases from the San Juan and Powder River Basins. AAPG Bulletin. 2002. 86(11): 1853-1890

Berg R R. Capillary pressures in stratigraphic traps. AAPG Bulletin. 1975. 59(6): 939-956

Cheng S Q and Chen M Z. Numerical simulation of two dimensional two phase non-Darcy slow flow. Petroleum Exploration and Development. 1998. 25(1): 41-45 (in Chinese)

Chen Y M, Zhou J, Liu W X, et al. Experimental demonstration of the nonDarcy phenomenon during low velocity flow through porous media. Journal of Chongqing University (Natural Science Edition). 2003. 23(supplement): 59-60 (in Chinese)

Civan F. Leaky-tank reservoir model including the non-Darcy effect. Journal of Petroleum Science and Engineering. 2000. 28(3): 87-93

Cui H Z, Yao G Q and Zhou F D. Type and the variety characteristics of relative permeability curve in low permeable glutenite oil reservoirs. Geological Science and Technology Information. 2003. 22(1): 88-91 (in Chinese)

Deng Y E, Wang Y C, Liu C Q, et al. Calculating relative permeability of
non-Darcy flow in low permeability media. Journal of Southwest Petroleum Institute. 2000. 22(3): 34-36 (in Chinese)

Deng Y Z and Liu H Q. Experiment on starting pressure gradient of oil and water two phases flow in low permeability core. Oil Drilling \& Production Technology. 2006. 28(3): 37-40 (in Chinese)

Dong D P, Feng W G, Zhao J F, et al. A method for relative permeability calculation considering start-up pressure gradient. Natural Gas Industry. 2007. 27(10): 95-96 (in Chinese)

Feng W G. Current research and prospect on the non-Darcy low-velocity flow. Petroleum Exploration and Development. 1986. 13(4): 76-80 (in Chinese)

Han H B, Cheng L S, Zhang M L, et al. Physical simulation and numerical simulation of ultra-low permeability reservoir in consideration of starting pressure gradient. Journal of China University of Petroleum (Edition of Natural Science). 2004. 28(6): 35-41 (in Chinese)

Hou X C, Wang Y R and Yang Q Y. A new calculation method for unstable state oil/water relative permeability curve. Petroleum Geology \& Oilfield Development in Daqing. 2008. 27(4): $54-56$ (in Chinese)

Huang Y Z. Nonlinear percolation features in low permeability reservoirs. Special Oil \& Gas Reservoirs. 1997. 4(1): 9-14 (in Chinese)

Huang Y Z. Flow Mechanism of Low Permeability Formation. Beijing: Petroleum Industry Press. 1998. 83-94 (in Chinese)

Huang Y Z, Wang E Z and Han X M. Non-Darcy percolation mechanism for seepage in low-permeability rock. Journal of Tsinghua University (Science and Technology). 2005. 45(9): 1202-1205 (in Chinese)

Jia Z Q, Wang Y F, Fu J L, et al. Characteristics of non-Darcy percolation under the condition of low-permeability and low-velocity. Journal of Daqing Petroleum Institute. 2001. 25(3): 73-76 (in Chinese)

Jiang L Z, Gu J Y and Guo B C. Characteristics and mechanism of low permeability clastic reservoir in Chinese petroliferous basin. Acta Sedimentologica Sinica. 2004. 22(1): 16-18 (in Chinese)

Johnson E F, Bossler D P and Naumann V O. Calculation of relative permeability from displacement experiments. Petroleum Transactions, AIME. 1959. 216: 370-372

Law B E. Basin-centered gas systems. AAPG Bulletin. 2002. 86(11): 1891-1919

Law B E and Curtis J B. Introduction to unconventional petroleum systems. AAPG Bulletin. 2002. 86(11): 1851-1852

Li D P. Development of Low-permeability Sandstone Oilfields. Beijing: Petroleum Industry Press. 1997. 1-13 (in Chinese)

Li N, Tang X G, Zhang Q X, et al. Experimental study on low-velocity non-Darcy gas flow in low-permeability reservoir. Natural Gas Exploration \& Development. 2003. 26(2): 49-55 (in Chinese)

Lin Y B and Shi X B. An experimental study on oil and water relative permeability in ultra-low permeable reservoirs. Petroleum Geology \& Oilfield Development in Daqing. 2000. 19(2): 30-33 (in Chinese)

Li Y A, Chang G D, Xiao H, et al. Methods to determine the threshold pressure gradient for low permeability reservoir and their application. Journal of Yangtze University (Natural Science Edition), Sci \& Eng Volume. 2007. 4(2): 170-173 (in Chinese)

Li Z F, He S L and Men C Q. Study on the non-Darcy percolation rules in the low permeable oilfield. Well Testing. 2005. 14(3): 14-18 (in Chinese)

Luo Z F, Huang B G, Wang N T, et al. A calculation method for relative permeability of low permeability reservoir. Fault-Block Oil \& Gas Field. 2007. 14(1): 47-49 (in Chinese)

Merrikh A A and Mohamad A A. Non-Darcy effects in buoyancy driven flows in an enclosure filled with vertically layered porous media. International Journal of Heat and Mass Transfer. 2002. 45(21): 43054313

Miller R J and Low P F. Threshold gradient for water flow in clay system. Soil Science Society of America Journal. 1963. 27(6): 605609

Min Q, Jin G X and Rong C L. Study and Practice of Low-permeability Oil and Gas Field. Beijing: Petroleum Industry Press. 1998. 1-5 (in 
Chinese)

Olsen H W. Deviations from Darcy's law in saturated clays. Soil Science Society of America Journal. 1965. 29(2): 135-140

Pang X Q, Jin Z J, Zeng J H, et al. Prediction of the distribution range of deep basin gas accumulations and application in the Turpan-Hami Basin. Energy Exploration \& Exploitation. 2002. 20(2-3): 253-286

Pascal J P and Pascal H. Non-linear effects on some unsteady nonDarcian flows through porous media. International Journal of NonLinear Mechanics. 1997. 32(2): 361-376

Prada A and Civan F. Modification of Darcy's law for the threshold pressure gradient. Journal of Petroleum Science and Engineering. 1999. 22(4): 237-240

Ran L, Zhang L H and Zhou M. Calculation method of relative permeability curve in low permeability reservoir. Special Oil \& Gas Reservoirs. 2006. 13(5): 65-67 (in Chinese)

Ren X J, Yan Q L, He Q X, et al. The experimental study of characteristics of gas flow in tight formations. Journal of Xi'an Petroleum Institute. 1997. 12(3): 22-25 (in Chinese)

Ruan M and He Q X. Determination of the critical point of non-Darcy flow through low permeability porous media and judgment of Darcy flow and non-Darcy flow. Journal of Xi'an Petroleum Institute. 1999a. 14(3): 9-10 (in Chinese)

Ruan M and He Q X. A study of the overall criterion for judging the nonDarcy flow through low permeability porous media. Journal of Xi'an Petroleum Institute. 1999b. 14(4): 46-48 (in Chinese)

Ruan M, He Q X and Ren X J. Low permeability reservoir percolation characteristics and their influence on oil field development. Special Oil \& Gas Reservoirs. 1998. 5(3): 23-28 (in Chinese)

Song F Q and Liu C Q. A method for calculating the relative permeabilities of water and oil in low permeability reservoirs. Journal of Xi'an Petroleum Institute. 2000. 15(1): 10-12 (in Chinese)

Song F Q and Liu C Q. A new model for flow in low-permeability porous media. Xinjiang Petroleum Geology. 2001. 22(1): 10-12 (in Chinese)

Soni J. An experimental evaluation of non-Darcian flow in porous media. Journal of Hydrology. 1978. 38(3-4): 231-241

Surdam R C. Pressure regimes in the Upper Cretaceous shales and sandstones in the Washakie Basin. In: Wyoming Field Conference Guidebook. Wyoming Geological Association. 1995

Surdam R C. Fluid-flow regimes and sandstone/shale diagenesis in the Powder River Basin, Wyoming. In: Siliciclastic Diagenesis and Fluid Flow: Concepts and Applications. SEPM Special Publication. 1996. No. 55

Wang G X, Xie J Y, Li J L, et al. On relative permeability curves and production characteristics of reservoirs. Xinjiang Petroleum Geology. 2004. 25(3): 301-304 (in Chinese)
Williams K E, Lerche I and Maubeuge F. Unconventional gas traps: Low permeability sands and gas accumulations. Energy Exploration \& Exploitation. 1998. 16(1): 1-87

Wu H Y, Liang X D, Xiang C F, et al. Characteristics of syncline reservoir and mechanics of hydrocarbon accumulation in Songliao Basin. Science in China (Series D: Earth Science). 2007. 37(2): 185 191 (in Chinese)

Wu J C, Yuan M, Zhang J C, et al. Characteristics of single phase low velocity non-Darcy flow in a low permeability reservoir in eastern Daqing. Journal of Daqing Petroleum Institute. 1999. 23(2): 83-84 (in Chinese)

Xue Y, Shi J P and He C Z. Analysis of low velocity non-Darcy flow mechanism. Petroleum Exploration and Development. 2001. 28(5): 102-104 (in Chinese)

Yang H, Dou W T, Yu J, et al. New technology for exploration of lowpermeability oil reservoirs in the Ordos Basin. China Petroleum Exploration. 2003. 8(1): 32-40 (in Chinese)

Yan Q L, He Q X, Wei L G, et al. A laboratory study on percolation characteristics of single phase flow in low-permeability reservoirs. Journal of Xi'an Petroleum Institute. 1990. 5(2): 1-6 (in Chinese)

Yao Y D and Ge J L. Study on non-Darcy flow pattern in low permeability oil reservoir. Xinjiang Petroleum Geology. 2000. 21(3): 213-215 (in Chinese)

Yao Y D and Ge J L. New pattern and its rules of oil non-Darcy flow in porous media. Oil Drilling \& Production Technology. 2003. 25(5): 40-42 (in Chinese)

Zhang $\mathrm{J} \mathrm{C}$ and Wang $\mathrm{Z} \mathrm{X}$. Formation mechanism of abnormal pressures in deep-basin gas accumulation. Petroleum Exploration and Development. 2003. 30(1): 28-30 (in Chinese)

Zhang X L, Zha M and Wang P. Oil/water inversion and its genetic mechanism in the higher portions of the single sandstone body. Acta Sedimentologica Sinica. 2006. 24(1): 148-152 (in Chinese)

Zhang X W and Yin J H. Features of oil water relative permeability curves for low permeability sandstone reservoir. Special Oil \& Gas Reservoirs. 1999. 6(2): 27-31 (in Chinese)

Zhao W Z, Zou C N, Wang Z C, et al. The intension and signification of "Sag-wide Oil-bearing Theory" in the hydrocarbon-rich depression with terrestrial origin. Petroleum Exploration and Development. 2004. 31(2): 5-13 (in Chinese)

Zhu Z Q, Zeng J H, Wang J J, et al. An experimental study on flow characteristics of oil migration in low-permeability sandstone under condition of oil accumulation. Geoscience. 2009. 23(4): 755-760 (in Chinese)

(Edited by Hao Jie) 